\title{
Exploring the Relationship Between Factors That Contribute to Interactive Engagement and Academic Performance
}

\author{
Malefyane Tlhoaele (corresponding author) \\ Tshwane University of Technology, Teaching and Learning with Technology \\ Private Bag X680, Pretoria 0001, South Africa \\ E-mail: tlhoaelemj@tut.ac.za
}

\begin{abstract}
Adriaan Hofman
University of Groningen, RUG/UOCG, Landleven 19747 AD Groningen, The Netherlands w.h.a.hofman@rug.nl

Koos Winnips

University of Groningen, RUG/UOCG, Landleven 19747 AD Groningen, The Netherlands E-mail: koos.winnips@rug.nl
\end{abstract}

Yta Beetsma

University of Groningen, RUG/UOCG, Landleven 19747 AD Groningen, The Netherlands E-mail: y.beetsma@rug.nl

Received: August 27, 2014 Accepted: September 9, 2014 Published: November 6, 2014 doi:10.5296/jet.v2i1.6577 URL: http://dx.doi.org/10.5296/jet.v2i1.6577 


\begin{abstract}
In an educational context, technology can prompt interactive engagement only when it is used in conjunction with interactive engagement methods. This study, therefore, examines the relationships between factors that contribute to higher levels of interactive engagement and performance, such as interactive engagement methods, technology, intrinsic motivation and deep learning. Five hundred and twenty-six (526) higher education students participated in this study. With structural equation modelling, the authors test the conceptual model and identify satisfactory model fit. The results indicate that interactive engagement methods, technology and intrinsic motivation have significant relationships with interactive engagement; deep learning mediates the relationships of the other variables with performance.
\end{abstract}

Keywords: Interactive engagement methods; technology; interactive engagement; deep learning; academic performance

\title{
1. Introduction
}

In recent years, educational technology has affected the communication approaches in the education environment, that is, it has influenced the way lecturers deliver their content material as well as the way students learn. Using educational technology in a classroom provides lecturers and students with dynamic new teaching and learning strategies and also makes a lesson more interactive and collaborative. However, educational technology interventions should be shaped by educational needs as opposed to technological concerns. Therefore, when appropriately used, educational technologies such as clickers and learning management systems among others, help students to develop the necessary 21 st century skills such as working in teams and applying knowledge to problem solving, which they need in order to succeed in the global workforce. Like many other countries worldwide, South Africa also has a need to understand the impact of technology-enhanced learning environments on students learning and as such, has a growing demand for technology-enhanced learning opportunities in the 21 st century. This notion is consistent with what is indicated in South Africa's National Plan for Higher Education document: "To produce graduates with skills and competences required to participate in the modern world in the 21st century" (Ministry of Education, 2001:18). Thus, to produce such graduates, South African institutions need to follow and adopt global education trends in technology and innovation (Damoense, 2003).

In the preceding section it is indicated that educational technologies make learning more interactive. However, a high level of interactive engagement reached with the support of these technologies, requires parallel uses of interactive engagement methods that prioritise interactive engagement themselves. Technology-enhanced interactive engagement methods include various teaching methods designed to encourage the development of students' critical thinking and idea sharing. These methods have been globally investigated: for example, Mazur (1997, 2009) used clickers to test students' problem-solving ability using Peer Instruction and traditional lectures. In his findings, students in the Peer Instruction classes (using clickers) scored higher on the test as a whole. Though, it should be noted that it is not technology as such that made a difference, but it is the combination of pedagogy, content, and technology knowledge that made a difference in test scores. This implies that, technology facilitates 
interactive engagement effectively. Therefore, to continue advancing understanding in this realm, the current study pursues an investigation of how interactive engagement methods and technology mediated by intrinsic motivation relate to interactive engagement, deep learning and academic performance which has not been investigated in previous research.

The degree to which students are motivated to engage interactively in learning activities depends on their expectation of the inherent satisfaction and value they can gain from each activity. Lecturers thus need to design activities which arouse students' curiosity and encourage them to construct their own understanding of the content (Keller \& Suzuki, 2004; Pintrich \& Schunk, 1996). If they can, students will develop a desire to interact with their peers, exchanging ideas to learn more about the topic. Since motivation represents an important component in attaining high levels of interactive engagement and academic performance, we pose it as a central mediating variable, such that students need motivational strategies (including intrinsic motivation) to maintain their interactive engagement and improve their performance. Even if in some cases, teaching methods such as collaborative learning directly affect interactive engagement, motivation is still required as an intermediate variable, because students are more motivated to participate in intrinsically motivating activities. The success of interactive engagement often depends on how motivated students are. When students are intrinsically motivated, they become actively involved in group and class discussions. In general, intrinsically motivated students also are more likely to employ deep learning strategies than are extrinsically motivated students (Baker, 2004). In accordance with Ames and Archer (1988), intrinsic motivation in particular contributes positively to the learning process and learning quality.

In addition to intrinsic motivation, Lublin (2003) asserts that the teaching method a lecturer uses encourages students to adopt a specific type of learning approach. Marton and Säljö (1976) distinguish deep and surface approaches to learning. The former, according to Entwistle (2005), involves understanding the meaning of course content. When a lecturer designs activities that arouse students' curiosity, they will likely ask higher-level questions and relate their ideas to previous knowledge and experience; consequently, improving their academic performance. Damoense (2003) also reiterates that these activities should be integrated with technology to achieve a high level of both interactive engagement and performance. The works of Phan (2009) and Floyd et al. (2009), for example, show that students who have high level of deep learning tend to have improved academic performance. Based on Phan's and Floyd et al.'s findings, we consider deep learning as an important mediator which could encourage and motivate students' development from surface to deep learning approaches. A surface learning approach relies on rote learning and memorisation (Richardson, 2005), and students using this approach are in most cases not motivated or even interested in understanding the course content.

\section{Conceptual Framework}

We present the conceptual framework for this study in Figure 1; it identifies the proposed causes of interactive engagement and integrates the principles of constructivist learning. Our model assumes that interactive engagement methods and technology have positive effects on 
intrinsic motivation. It also indicates that intrinsic motivation has a positive effect on interactive engagement, deep learning and academic performance.

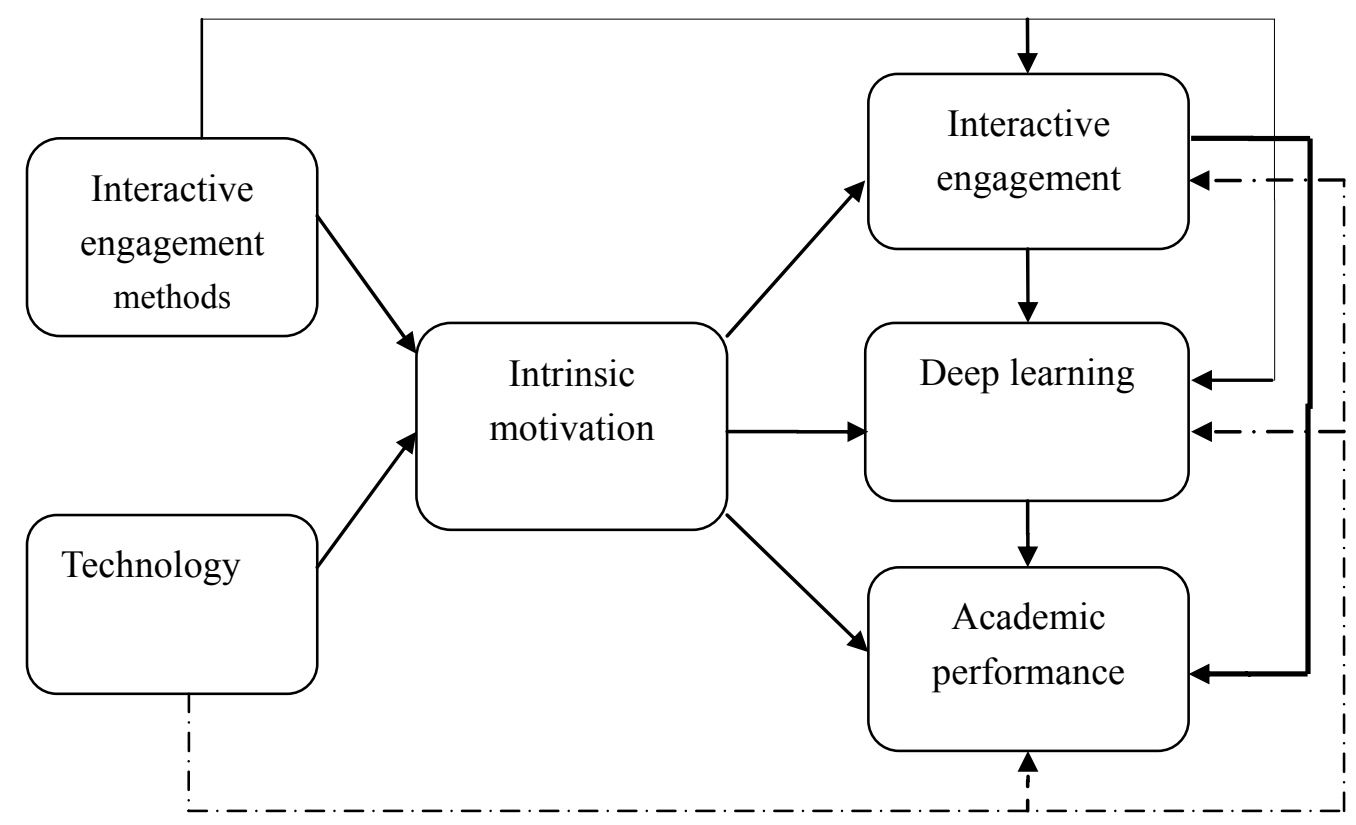

Figure 1. Conceptual framework

In this section we discuss the key variables in the current study starting with interactive engagement methods followed by technology. Thereafter, we discuss interactive engagement, intrinsic motivation and deep learning.

\subsection{Interactive Engagement Methods}

A large body of research has been conducted on various interactive engagement methods. These studies reported that interactive engagement methods promote interaction among students and with lecturers (Perkins \& Saris, 2001; Yoder \& Hochevar, 2005), as well as enhancing conceptual understanding, leading to improved academic performance (Hake, 1998, 2007; Mayer, 2009; Mazur, 1997, 2009; Ullah \& Wilson, 2007). The most practical confirmation of these benefits comes from Hake (1998), who collected pre- and post-test scores on the Force Concept Inventory from 6,542 students. The results showed that the interactive engagement courses were more effective than the non-interactive engagement (traditional) courses, which in turn improved students' academic performance.

Interactive engagement methods emphasise the social aspects of learning in that students work together through discussions and problem solving, rather than independent learning. It is confirmed that some students learn more when they learn with others (Michael, 2006; McKeachie, 2002). As a result, some lecturers use various interactive engagement methods, to encourage interactive engagement and students' understanding of course content. Interactive engagement methods are defined here as the various methods designed to support the development of students' critical thinking and problem-solving skills. Any teaching method adopted represents an important determinant of the level of interactive engagement during the learning process: for example, Yoder and Hochevar (2005) argue that discussion 
strategies promote interactive engagement beyond traditional lectures, by encouraging the retention of information, motivating students to engage in further investigation and developing their thinking skills. That is, during discussions, students construct new understanding from the inputs and ideas of other students. The type of activity also influences how much classroom material is retained. To design such activities effectively, lecturers must consider the notion of constructive alignment, which encourages a deep approach to learning (Biggs, 1999; Biggs, Kember, \& Leung, 2001).

Recent research in these interactive engagement methods includes how they could be enhanced with technology to improve students' learning and performance: for example, Neo (2005) used cooperative learning to promote active learning where multimedia technology and the use of Web 2.0 tools such as blogs among others were incorporated within this learning environment. Students were expected to design a multimedia website as a team. Therefore, students had to depend on the capabilities of their team mates in order to produce the final website. The results indicated that integrating a multimedia project into the cooperative learning structure created a viable and effective approach to enhance student and learning. This example demonstrates ways in which technology-enhanced interactive engagement method could be used to enhance students' learning. It also supports Damoense's (2003) statement that, activities which inspire and facilitate interactive learning should be integrated with both interactive engagement methods and technology, if a high level of interactive engagement and performance need to be achieved.

\subsection{Technology}

Technology in educational institutions refers to an integrated framework of computers, software applications, multimedia content, web-based applications, clickers, learning management systems such as Blackboard, and other tools that can be used to enhance the teaching and learning process.

In accordance with Vrasidas and McIsaac (2001), technology is a tool that students use to construct knowledge and share their understanding of content. As a result, students' exposure to technological improvements has influenced their learning approaches and expectations on the services that should be made available to them (Hechanova \& Cementina-Olpoc, 2013; Zandvleit \& Fraser, 2004). The biggest challenge for higher education institutions would be to offer effective technology-enhanced teaching environments to meet students' changed expectations regarding the way they are taught (Mohr, Holtbrügge, \& Berg, 2012).

Previous research on educational technology indicates that technology that supports teaching has a slightly but significantly higher average effect size (0.31) than technology used for presentational and various uses (Hattie 2009). Similarly, Schmid et al.'s (2009) finding also revealed a greater effect size (0.40) regarding technology used for cognitive support compared to technology used for presentation of content. This implies that, for technology to be effective it must support teaching, encourage engagement between lecturers and students (Diogo, António, \& Nilza, 2011), and improved students' understanding. In their studies, Lavooy and Newlin (2003) illustrate effective uses of technologies, such as computer-mediated communication, and show how they can increase learning interactions, 
such as student-student or instructor-student activities. Also, Solvie and Kloek (2007) suggest that technology can be used to communicate, enhance and clarify course concepts and content while also engaging students with information, as is fundamental to constructivism. Therefore, an environment that encourages innovative uses of technology leads to improved teaching, learning and academic performance (Wishart \& Blease, 1999).

Effective technology-enhanced teaching in educational settings requires an understanding of how it affects students and their critical thinking (Schuck \& Kearney, 2008). Hence, lecturers need to recognise the advantages and restrictions of any technology they seek to use in classrooms. As Harris, Mishra, and Koehler (2009) caution, some technologies are better suited to certain learning activities and educational situations. For example, simulations are more appropriate for engineering courses that seek to demonstrate how the structure of a material changes at different temperatures. In turn, lecturers need sufficient knowledge and skills to choose appropriate technologies for their courses (Harris, et al., 2009).

On the basis of such research that indicates that technology makes teaching more effective, and thus leads to higher interactive engagement and academic performance, many higher learning institutions have adopted learning management systems, such as Blackboard, and other advanced educational technologies, such as clickers. Blackboard offers various tools, such as discussion boards, announcements and assessments; if used effectively, they can induce greater interactive engagement within and outside the classroom. Additionally, multimedia elements, such as videos, audio recordings and text, also can be incorporated into learning management systems to increase interactivity (Damoense, 2003; Gautreau, 2011). Accordingly, technology provides opportunities for lecturers to meet the needs of students with diverse learning styles, through the use of multiple media (Bryant \& Hunton, 2000). Also, clickers appear universally regarded as an effective technology for taking interactive engagement to a higher level (Burnstein \& Lederman, 2001; Draper \& Brown, 2004; Elliott, 2003; Perkins \& Turpen, 2009). From an examination of the literature, it became clear that there are different models that have been used to encourage interactive engagement through the use of clickers. Among others, Mazur (2009) used clickers for 'concept testing', while d'Inverno et al. (2003) also used clickers for tutorials with positive results.

\subsection{Intrinsic Motivation}

The role of motivation in higher education is emphasised by Kember, Ho and Hong (2012) who asserted that the type of motivation student have for a specific study, and the intensity of that motivation, will influence students' commitment and approach to study during the learning process. One of the leading human motivation theories in the literature is self-determination theory (SDT) which is widely tested and applied in various fields such as education among others. This theory affirms that, to understand why people participate in certain activities or behave in a particular manner, the different types of motivation need to be distinguished and understood as they would lead to varied outcomes (Ballmann \& Mueller 2008). However, SDT is beyond the scope of this study.

Sansone and Harackiewicz (2000) suggest a basic classification of motivation, as intrinsic or extrinsic, such that intrinsic motivation concerns active engagement with tasks that people 
find interesting and that, in turn, promote growth (Ryan \& Deci, 2000). Furthermore, intrinsically motivated students construct their own meanings and understanding on the basis of their prior experiences, according to a constructivist approach (Vrasidas \& McIsaac, 2001). That is, during the learning process, students compare what they are learning with what they know about a specific topic, and then decide whether to accept the new knowledge or hold fast to what they already know. During this decision-making process, lecturers must guide students to develop skills for building their own understanding, because through this process, students can attain higher levels of interactive engagement. In particular, collaboration and idea sharing can produce higher levels of interactive engagement, such that learning is realised. For students to achieve a high level of intrinsic motivation, lecturers need relinquish some of their power in terms of controlling the classroom (Holley \& Oliver, 2010), such that they grant students an opportunity to construct their own understanding of the content. This autonomy should also improve student's self-efficacy. In contrast, extrinsically motivated people perform an activity to attain a specific outcome, such as higher scores, or avoid a punishment.

\subsection{Interactive Engagement}

Interactive engagement in this study is defined as a process that encourages student-peer and student-lecturer participation inside and outside the classroom. Interactive engagement is realised within specific teaching methods such as collaborative and cooperative learning among others. Kearsley and Shneiderman (1998) argue that even if interactive engagement can occur without technology, it can be more effectively facilitated through technology, providing students with experiences which are difficult to provide in face-to-face environment: for example technology has the power to bring students together with experts or other students worldwide to foster interaction (Winn, 2002). Additionally, the study conducted by Patterson, Kilpatrick, and Woebkenberg (2010), where clicker technology was used to engage all students in a large classroom, showed an increased degree of interactive engagement in the classroom. Mishra and Koehler (2006) suggest that lecturers who decide to use technology as a mode of content delivery in order to encourage interactive engagement, learning and academic performance, should consider using technology pedagogical content knowledge (TPACK) as a framework. This framework requires lecturers to understand pedagogical methods that use technology in constructive ways to deliver the content. This framework could be integrated into the three main learning interactions which were identified by Moore (1989) as early as 1989: learner-content, learner-instructor and learner-learner. These learning interactions are necessary for leading to higher levels of interactive engagement in a classroom and ultimately to improved academic performance.

First, interactions of students with the course content can be realised in various forms, such as taking notes or summarising while reading content material. Second, interactions of students with teachers take place when a lecturer delivers content, whether through face-to-face discussions, lectures or discussions held in learning management systems such as Blackboard. Such interactions might be initiated by students, who request clarification about course content, or by lecturers, who pose questions to prompt discussions. Questions that prompt discussions are imperative for stimulating interactive engagement and indicating the degree 
to which students understand the content. The discussions also give students opportunities to revise their comprehension of content material, which they might not previously have understood fully. The discussions initiated by lecturers produce additional activities, such as further explanations, disagreements and mutual agreements among students, which can stimulate knowledge construction (Dillenbourg, 1999; Slof, Erkens, Kirschner, Jaspers, \& Janssen, 2010; Vrasidas \& McIsaac, 2001). Thus, interactive engagement originates from discussions in the environment in which learning transpires.

Third, student-student interactions occur mostly when students work on activities in groups of two or more, whether during face-to-face or through online discussions. These three learning interactions are used in every educational institution though, the degree to which they are used and the mode of delivery differ from one institution to another as well as from one lecturer to another within an institution.

\subsection{Deep Learning}

Motivating students and engaging them interactively in their own learning and encouraging them to construct their own understanding of content seem to be a central aim of every educational institution. Therefore, lecturers need to acknowledge the different approaches (deep and surface) to learning that students demonstrate. Though, the same student might adopt a deep or a surface approach to different activities, depending on their (activities) nature (Richardson, 2005). That is, students might prefer a specific approach, but the design of the learning opportunity (Richardson, 2005) and the circumstances of the learning environment can encourage them to adopt particular approaches to learning. Furthermore, Peters, Jones, and Peters (2007) emphasise the importance of adjusting teaching methods and assessments to motivate students to apply a deep approach to learning. A deep approach to learning can be realised through an intention to understand the content. In their study, Coller and Scott (2009) assessed the effectiveness of the video-game course on students' learning. They indicate that it is not easy to compare the degree of learning that takes place in the game-based course with that of traditional numerical methods. As a result, instead of asking student questions on specific topics, they requested them to create concept maps on numerical methods. The results revealed that students in this course demonstrated deeper learning as compared to students in a traditional class using text-book method. In this case a concept map explained what students understood about numerical methods.

Similarly, Jaffer, Ng'ambi, and Czerniewicz (2007) used interactive excel spreadsheets combined with online discussions, short essays, reports and presentations to develop students' learning in an economics course. These activities empowered students to develop understanding of economics through writing in economics. Jaffer et al. (2007) state that, even though it was difficult to measure the impact of these tutorials, they realised that the interactive spreadsheets were effective teaching tools because students' focus was now on real economics issues rather than processes and procedural issues. In addition, the online feedback that lecturers provided during the process of drafting articles, improved the quality of articles produced by students during the learning process. This again supports the notion that when educational technology is used for students' cognitive support, students are likely 
to adopt deep learning approached. Consequently, giving students activities that stimulate their critical thinking encourages interactions among them, representing a substantial form of encouragement for deep learning (Offir, Lev, \& Bezalel, 2008) and thus improved academic performance.

\section{Research question and hypotheses}

We investigate the relationship of factors that influence the attainment of a high level of interactive engagement and improved academic performance. Thus, we specify our main research question as follows: How do interactive engagement methods and technology, mediated by intrinsic motivation, relate to interactive engagement, deep learning and academic performance? To answer this question, we formulate four separate hypotheses, predicting direct, mediating and positive effects.

H1. Interactive engagement methods and technology have direct positive effects on interactive engagement.

H2. Interactive engagement has a direct positive effect on academic performance.

H3. Deep learning has a positive effect on performance.

H4. The effects of interactive engagement methods and technology on performance are mediated by intrinsic motivation, interactive engagement and deep learning.

\section{Methods}

The current research is a quantitative study using survey methods to answer the research question. The details about context and participants, instruments and measurements as well as data analysis are presented in the following sub-sections.

\subsection{Context and Participants}

This study was conducted in a higher education institution in Gauteng, South Africa. Participants were selected from three departments (management sciences, engineering and science). At the time of the study, participants also had used Blackboard as a learning management system since their first semester at the university, and some of them had also used clickers for group and class discussions. The minimum experience that the students had using technology-supported learning material was two semesters and the maximum was four semesters.

Six-hundred and fifteen students (615) were invited to participate in the study with $526(86 \%)$ responding to the questionnaire including 246 male students (47\%) and 280 female students (53\%). Of these participants, 285 (54\%) were between 18 and 21 years of age, $231(44 \%)$ were between 21 and 23 years and $10(2 \%)$ were between 23 and 25 years. In addition, 153 (29\%) represented management sciences students, 196 (37\%) came from engineering and 177 $(34 \%)$ were from the science department. All participants completed the consent forms, as required by the university ethics committee. The questionnaires were distributed in classrooms after lectures; students were requested to complete and submit their responses at their next class meeting. 


\subsection{Instruments and Measurements}

We developed a questionnaire based on previous studies by Kaufman, Sutow, and Dunn (1997), Liawm (2008), Pintrich, Smith, Garcia, \& McKeachie (1991) and Biggs et al. (2001). Five categories of questions, spread across 24 questions, measured interactive engagement methods, technology, motivation, deep learning and interactive engagement. Since the study was conducted in South Africa, some of the terms and technologies used were changed to suit the context. However, the scales used were based on the original authors of the questionnaires. The interactive engagement methods -related items were adapted from Kaufman, Sutow, and Dunn (1997) and consisted of seven questions (e.g. 'interactive engagement methods encourage sharing of knowledge and experience with other students'). The category focused on technology was adapted from Liawm (2008) and featured four questions (e.g. 'I believe technology can improve learning efficiency and performance'). The four questions in the interactive engagement category also were adapted from Liawm (2008) (e.g. 'I enjoy working with other students in an academic project'). For the preceding three measures, we used five-point scales $(1=$ 'completely disagree,' and $5=$ 'completely agree'). The motivation category (Pintrich, Smith, Garcia, \& McKeachie, 1991) used four questions (e.g. 'I prefer activities that are challenging so that I can learn new things') and a seven-point scale ( $1=$ 'not at all true of me,' and $7=$ 'very true of me'). Finally, for the deep learning category (Biggs, et al., 2001), we used five questions (e.g. 'I test myself on important topics until I understand them completely'), with a five-point scale $(1=$ 'this item is never or only rarely of me,' and $5=$ 'this item is always or almost always true of me"). Although deep learning originally used ten questions, we selected five which we found more relevant to our study. Table 1 illustrates the descriptive statistics of the focal variables.

Table 1. Descriptive statistics

\begin{tabular}{|l|c|c|c|c|}
\hline Variables & Nitems & Mean & SD & Cronbach's $\alpha$ \\
\hline Appropriate teaching methods & 7 & 30.43 & 2.25 & .73 \\
\hline Technology & 4 & 18.23 & 1.51 & .72 \\
\hline Intrinsic motivation & 4 & 17.62 & 1.82 & .77 \\
\hline Deep learning & 5 & 21.45 & 2.03 & .76 \\
\hline Interactive engagement & 4 & 15.84 & 1.79 & .80 \\
\hline
\end{tabular}

Furthermore, we used test scores to measure students' academic performance. Because students represented three different academic departments, their scores were standardised and transformed into z-scores. Table 2 shows the descriptive statistics of the test scores.

Table 2. Descriptive statistics: Scores by department

\begin{tabular}{|l|c|c|c|c|c|}
\hline Department & N Students & N items & Mean & SD & Cronbach's $\alpha$ \\
\hline Management Sciences & 153 & 9 & 70.25 & 8.10 & .75 \\
\hline Engineering & 196 & 9 & 70.04 & 7.63 & .77 \\
\hline Science & 176 & 9 & 69.21 & 6.90 & .62 \\
\hline
\end{tabular}

Cronbach's alpha values served to identify the internal consistency of the variables (see Table land Table 2). The scales presented in Table 1 are reliable with Cronbach's Alpha $=.72$ 
(Technology) to .80 (Interactive engagement). In Table 2, the scales for management sciences and engineering exhibited good internal reliability. However, the reliability for science was lower, with an internal reliability of .62 .

\subsection{Data Analysis}

To explore the relationships among the variables, we used LISREL 8.8 (Jöreskog \& Sörbom, 2006), a statistical software package that supports structural equation modelling. LISREL allows us to see if the theoretical model (Figure 1) fits the data and to explore the direct and indirect effects within the model. In a path diagram (Figure 2), all significant relationships are represented. The hypothesised relations among variables are indicated by arrows, signifying predictive or correlational relations. Besides presenting the nature and direction of causal relationships, a path diagram (Figure 2) also includes estimates of the strength of those relationships - the path coefficients. The analysis began with a calculation of the relationships among all the observed variables in the model, concurrent with interactive engagement methods and technology as the independent variables. Interactive engagement and performance appeared as dependent variables; while intrinsic motivation and deep learning represented mediating variables.

Because chi-square tests are sensitive to sample size, Hu and Bentler (1999) suggest that in addition to $\chi^{2}$, researchers should use at least two other types of indices to evaluate model fit. Following the advice of Matsunga (2010) and Kline (2005), we therefore evaluated the fit of the conceptual model (Figure 1) according to the $\chi^{2}$ value, root mean square error of approximation (RMSEA), standardised root mean square residual (SRMR) and comparative fit index (CFI). These three indices (RMSEA, SRMR and CFI) are the least sensitive to sample size, model misspecification and parameter estimates (Hooper, Coughlan, \& Mullen, 2008). As standard values that indicate good fit, we follow the general consensus and require RMSEA values close to .06 (Hu \& Bentler, 1999), SRMR less than .05 (Diamantopoulos \& Siguaw, 2000) and a CFI greater than or equal to .95 (Hu \& Bentler, 1999).

\section{Results and Discussion}

This study investigated the relationship of factors that influence the attainment of a high level of interactive engagement and improved performance. Four hypotheses predicting direct, mediating and positive effects were formulated to assist in the investigation. The following section provides the results and the discussion for this examination.

We posited that interactive engagement methods and technology have positive effects on interactive engagement, and in support of $\mathrm{H} 1$, the results confirmed both these positive, direct relationships $(p<.01)$. That is, when lecturers use interactive engagement methods and technologies, it improves students' interactive engagement. In addition, we predicted that interactive engagement would have a direct positive effect on academic performance. However, the results revealed no such direct relationship, so we must reject $\mathrm{H} 2$; instead, we observed an indirect relationship through deep learning. Deep learning had a positive effect on performance, in support of H3. For our mediating effects H4, in which we hypothesised that the effect of interactive engagement methods and technology on performance would be 
mediated by intrinsic motivation, interactive engagement and deep learning, we found partial support, because intrinsic motivation did not mediate the impact of the independent variables on academic performance.

The proposed model (Figure 1 ) did not achieve satisfactory fit $\left(\chi^{2}=6.27, p=.04\right.$, df $=2$, $\mathrm{RMSEA}=.06 . \mathrm{SRMR}=.02, \mathrm{CFI}=.97)$. To improve this fit, we added the relationship between interactive engagement methods and performance, but we also removed the non-significant relationships between intrinsic motivation and performance and between technology and deep learning from the model. Figure 2 illustrates the final model with the relationship coefficients; it provides satisfactory fit: $\chi^{2}=5.43, p=.14, \mathrm{df}=3, \mathrm{RMSEA}=.04$, $\mathrm{SRMR}=.02$, and $\mathrm{CFI}=.99$

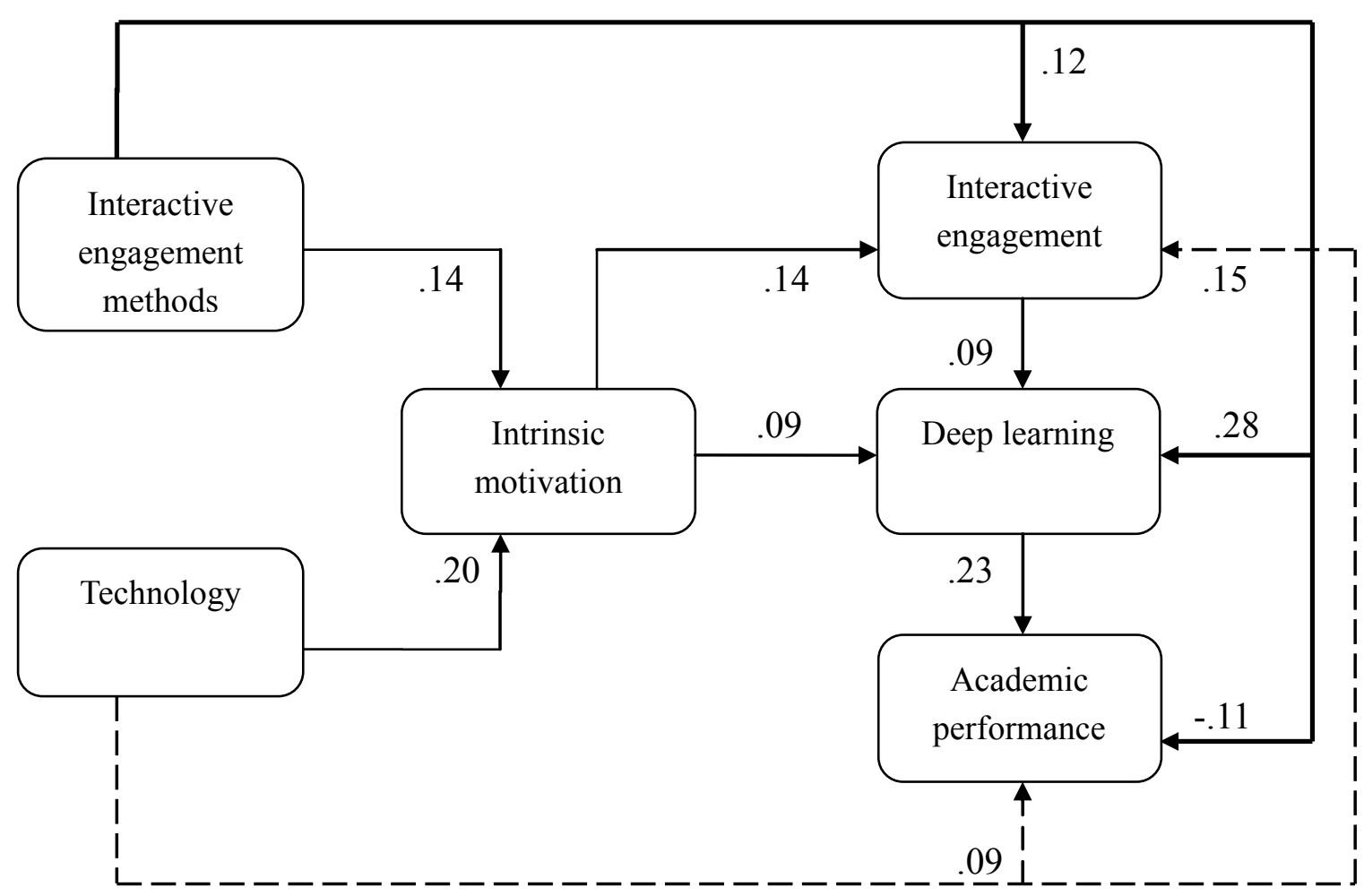

Figure 2. Final structural model with standardised effects

Note: Paths denoted by dashed lines indicate direct effects of technology on interactive engagement and performance (.15 and .09 , respectively); bold solid lines specify direct effects of interactive engagement methods on interactive engagement, deep learning and performance $(.12, .28$, and -.11 , respectively). The faint solid lines indicate the indirect effects of interactive engagement method and technology on interactive engagement, deep learning and academic performance.

Even after the improvement of the model, the results were still in support of H1, H3 and partially in support of H4. All the same, H2 was again not supported. Subsequently, we considered the estimates of the strength of all relationships in the model starting with the strongest relationships as indicated below. 
Accordingly, the direct effect of interactive engagement methods on deep learning $(\gamma=.28)$ was the strongest relative effect in the final model (Figure 2), followed by the effect of deep learning on academic performance $(\beta=.23)$. The direct effect of technology on intrinsic motivation $(\gamma$ $=.20)$ was fairly strong, whereas the direct effect of interactive engagement methods on intrinsic motivation was only moderate $(\gamma=.14)$. Similarly, the direct effect of technology on interactive engagement $(\gamma=.15)$, the direct effect of intrinsic motivation on interactive engagement $(\gamma=.14)$, as well as the direct effect of interactive engagement $(\gamma=.12)$, were also moderate. The weakest, but still significant $(p<.05)$, direct effect moved from technology to academic performance $(\gamma$ $=.09)$, intrinsic motivation to deep learning $(\gamma=.09)$, as well as from interactive engagement to deep learning $(\beta=.09)$. In addition to the negative direct effect of interactive engagement methods on academic performance $(\gamma=-.11)$, we observed an indirect effect of intrinsic motivation on academic performance, through deep learning (.02).

The aim of this study was to answer our central research question: How do interactive engagement methods and technology, mediated by intrinsic motivation, relate to interactive engagement and academic performance? As Harris, Mishra, and Koehler (2009) indicate, course content determines the appropriate uses of existing technologies and shapes new technologies. Similarly, the presentation of this content depends on the benefits and limitations of the technology that a teacher uses. Our findings indicate that the direct effects of interactive engagement methods and technology complement each other in terms of their effect on students' attainment of high levels of interactive engagement. The extent of teacher engagement also contributes to higher student interactive engagement, because such teachers combine content and technology to benefit their students. Teachers who truly hope to increase interactive engagement in their classrooms must vary their interactive engagement methods, this is in line with Francisco, Nicoll, and Trautmann's (1998) findings that incorporating various teaching methods improves students participation. Similarly, previous studies have shown that technologies such as clickers (Draper \& Brown, 2004; K. Perkins \& Turpen, 2009) and learning management systems such as Blackboard (Gautreau, 2011) increase student interactivity. Technology seemingly has become a driving force for students' interactions. Although the stronger effect of technology on interactive engagement (.15), compared with the influence of interactive engagement methods on interactive engagement (.12), likely stems from modern students' general familiarity with technology, we argue that the success of these interactions lies with a well-structured, interactive engagement method.

The relatively strong relationship we find between interactive engagement methods and deep learning support Lublin's (2003) claims that a teaching method determines students' approach to learning. Using a variety of interactive engagement methods thus can lead to significantly improved learning. Students who prefer various methods take advantage of lecturers' uses of them to improve their deep learning skills, which led to their improved performance. Our results indicate that deep learning serves a significant function in the learning process, as evidenced by its strong effect on performance (.23) which is in support of H3. In most cases, students must use deep learning to understand the course content and improve their performance, as suggested in previous research as well (Duff, Boyle, Dunleavy, \& Ferguson, 2004; Floyd, Harrington, \& Santiago, 2009; Tarabashkina, 2011). Deep learning correlates 
positively with academic performance. In this sense, the direct effects of educational factors may have more impact on learning than technology does.

The notion of central mediation also appears to function through deep learning, not intrinsic motivation, in that deep learning mediates the effects of interactive engagement methods, technology, intrinsic motivation and interactive engagement on academic performance. This finding raises a concern: What enables deep learning to play the central mediation role that we predicted would be served by intrinsic motivation? Intrinsic motivation is an attitude variable, and positive attitudes usually emerge in response to frequent interesting activities. Because motivation thus depends on conditions, it should fluctuate during the learning process. Perhaps students began with high intrinsic motivation, but over time, their motivation declined, such that motivation could not play a crucial mediation role between the independent variables and academic performance.

Warburton (2003) argues that deep learning is associated with critical and independent thinking. Deep learning as a learning strategy needs to be developed; once acquired, students maintain this skill, because it allows them to transform new information into their own understanding, resulting in improved capabilities to apply learned principles to new situations. However, not all intrinsically motivated students acquire deep learning approach skills; those who do should achieve higher levels of performance. The students in this study acquired their skills through interactive engagement methods, used during their learning processes, as evidenced by the strong direct effect of interactive engagement methods on deep learning $\quad(\gamma=.28)$. Therefore, deep learning took over the mediating role. This important outcome emphasises that intrinsic motivation does not guarantee a high level of academic performance. Instead, students must go further and make sense of the content to achieve improved performance.

Finally, we note two additional, attention-grabbing outcomes. First, there was no direct relationship of interactive engagement and performance; its effect moved through deep learning. Interactive engagement alone cannot guarantee improved performance. Instead, learning must be realised first, before performance can improve. Second, interactive engagement methods have been associated with improved performance, but in our study, their direct effect on academic performance was negative. We consider a few possible explanations. Students who have not adjusted well to the teaching approaches, the confront might have become discouraged and performed poorly. Alternatively, successful students with more experience with interactive engagement methods may be less interested in high scores and more focused on understanding the course content. The influence of interactive engagement methods clearly is important though. We might even argue that, because of the strong relationship between interactive engagement methods and deep learning, the remaining effect of interactive engagement methods grew negative. No prior research offers similar results.

\section{Limitations and Conclusions}

The participants in this study were from three academic departments, such that the students were exposed to different faculties, course contents and prior knowledge, which might have influenced the results. Additional research might replicate our study but control for other variables, such as students' prior knowledge. The student consent forms also stated explicitly 
that students did not have to participate and could withdraw from the study at any time. Follow-up attempts to contact students who had not responded to the questionnaires prompted promises to respond but no actual input. We thus cannot provide description of students who did not respond to the questionnaire.

In conclusion, even with these limitations, this study offers a compelling model of the relationships between several variables and their relations to interactive engagement and performance. Overall, the results indicate that interactive engagement methods, technology and motivation all relate significantly to interactive engagement. Deep learning serves as a mediator of the relationships of the other variables with performance. In addition, we find a significant positive relationship of technology with academic performance. This study helps clarify the learning process; through a well-designed course and interactive activities, students become motivated to participate in the classroom, which leads to their better understanding of the course content and ultimately to improved performance.

\section{References}

Ames, C., \& Archer, J. (1988). Achievement goals in the classroom: Student's learning strategies and motivation process. Journal of Educational Psychology, 80(3), 260-267.

Baker, S. R. (2004). Intrinsic, extrinsic, and amotivational orientations: Their role in university adjustment, stress, well-being, and subsequent academic performance. Current Psychology, 23(3), 189-202.

Ballmann, J. M., \& Mueller. J. J. (2008). Using self-determination theory to describe the academic motivation of allied health professional-level college student. Journal of Allied Health, 37(2), 90-96.

Biggs, J. B. (1999). Teaching for Quality Learning at University. London: Society for Research into Higher Education and Open University. Open University Press.

Biggs, J. B., Kember, D., \& Leung, D. Y. P. (2001). The revised two factor study process questionnaire: R-SPQ-2F. British Journal of Educational Psychology, 71(1), 133-149. http://dx.doi.org/10.1348/000709901158433.

Brophy, J. E. (1987). Synthesis of research on strategies for motivating students to learn. Educational Leadership, 45(2), 40-48.

Bryant, S. M., \& Hunton, J. E. (2000). The use of technology in the delivery of instruction: implications for accounting educators and education researchers. Issues in Accounting Education, 15(1), 129-163. http://dx.doi.org/10.2308/iace.2000.15.1.129.

Burnstein, R., \& Lederman, L. (2001). Using wireless keypads in lecture classes. The Physics Teacher, 39(1), 8-11. http://dx.doi.org/10.1119/1.1343420.

Coller, B. D. \& Scott, M. J. (2009). Effectiveness of using a video game to teach a course in mechanical engineering, Computers \& Education, 53(3), 900-912. http://dx.doi.org/10.1016/j. compedu.2009.05.012. 
d'Inverno, R., Davis, H., \& White, S. (2003). Using a personal response system for promoting student interaction. Teaching Mathematics and its applications, 22(4), 163-169. http://dx.doi.org/10.1093/teamat/22.4.163.

Damoense, M. Y. (2003). Online learning: Implications for effective learning for higher education in South Africa. Australian Journal of Educational Technology, 19(1), 25-45

Diamantopoulos, A., \& Siguaw, J. A. (2000). Introducing LISREL. London: Sage Publications.

Dillenbourg, P. (1999). What do you mean by collaborative learning? In P. Dillenbourg (Ed.), Collaborative-learning: Cognitive and Computational Approaches (pp. 1-19). Geneva: Oxford: Elsevier.

Diogo C, António M., \& Nilza, C. (2011). Technology Enhanced Learning in Higher Education: Results from the design of a quality evaluation framework. Procedia - Social and Behavioral Sciences, 29, 893-902. http://dx.doi.org/10.1016/j.sbspro.2011.11.319.

Draper, S. W., \& Brown, M. I. (2004). Increasing interactivity in lecturers using an electronic voting system. Journal of Computer Assisted Learning, 20(2), 81-94. http://dx.doi.org/10.1111/j.1365-2729.2004.00074.x.

Duff, A., Boyle, E., Dunleavy, K., \& Ferguson, J. (2004). The relationship between personality, approach to learning and academic performance. Personality and Individual Differences, 36(8) 1907-1920. http://dx.doi.org/10.1016/j.paid.2003.08.020.

Elliott, C. (2003). Using personal response system in Economics teaching. International Review of Economics Education volume, 1(1), 80-86.

Entwistle, N. (2005). Contrasting perspectives on learning. In F. Marton, D. Hounsell \& N. Entwistle (Eds.), The Experience of learning: Implications for teaching and studying in higher education. (3rd, Internet ed., pp. 3-22). Scotland: University of Edinburgh, Centre for Teaching, Learning and Assessment.

Floyd, K. S., Harrington, S. J., \& Santiago, J. (2009). The effect of engagement and perceived course value on deep and surface learning strategies. Informing Science: the International Journal of an Emerging Transdiscipline, 12, 181-190.

Francisco, J. S., Nicoll, G., \& Trautmann, M. (1998). Integrating multiple teaching methods into a general chemistry classroom. Journal of Chemical Education, 75(2), 210-213. http://dx.doi.org/10.1021/ed075p210.

Gautreau, C. (2011). Motivational factors affecting the integration of a learning management system by faculty. The Journal of Educators Online, 8(1), 1-25.

Hake, R. R. (1998). Interactive-engagement versus traditional methods: A six-thousand-student survey of mechanics test data for introductory physics courses. American Journal of Physics 66(1), 64-74. http://dx.doi.org/10.1119/1.18809

Hake, R. R. (2007). Six lessons from the Physics education reform effort. Latin American Journal of Physics Education, 1(1), 24-31. 
Harris, J., Mishra, P., \& Koehler, M. (2009). Teacher's technological pedagogical content knowledge and learning activity type: Curriculum-based technology integrated reframed. Journal of Research on Technology in Education, 41(4), 393-416.

Hechanova, R. M., \& Cementina-Olpoc, R. (2013). Transformational leadership, change management, and commitment to change: A comparison of academic and business organizations. Asia-Pacific Educational Research, 22(1), 11-19.

http://dx.doi.org/10.1007/s40299-012-0019-z.

Hattie, J. (2009). Visible learning: A synthesis of over 800 meta-analyses relating to achievement. London, UK: Routledge.

Holley, D., \& Oliver, M. (2010). Student engagement and blended learning: Portraits of risk. Computers \& Education, 54(3), 693-700. http://dx.doi.org/10.1016/j.compedu.2009.08.035.

Hooper, D., Coughlan, J., \& Mullen, M. R. (2008). Structural equation modelling: Guidelines for determining model fit. Electronic Journal of Business Research Methods, 6(1), 53-60.

Hu, L., \& Bentler, P. M. (1999). Cutoff criteria for fit indexes in covariance structure analysis: Conventional criteria versus new alternatives. Structural Equation Modeling, 6, (1) 1-55. http://dx.doi.org/10.1080/10705519909540118.

Jaffer, S., Ng'ambi, D. \& Czerniewicz, L. (2007). The role of ICTs in higher education in South Africa: One strategy for addressing teaching and learning challenges. International Journal of Education and Development using Information and Communication Technology, $3(4), 131-142$

Jöreskog, K., \& Sörbom, D. (2006). LISREL. Lincolnwood: Scientific Software International, Inc.

Kaufman, D., Sutow, E., \& Dunn, K. (1997). Three approaches to cooperative learning in higher education. The Canadian Journal of Higher Education, Volume XXVII (2, 3), 37-66.

Kearsley, G., \& Shneiderman, B. (1998). Engagement Theory: A framework for technology-based teaching and learning. Educational Technology, 38(5), 20-23.

Keller, J. M., \& Suzuki, K. (2004). Learner motivation and E-learning design: a multinationally validated process. Journal of Educational Media, 29(3), 229-239.

http://dx.doi.org/10.1080/1358t65042000283084.

Kember, D., Hong, C., \& Ho, A. (2008). Characterising the motivational orientation of students in higher education: A naturalistic study in three Hong Kong universities. British Journal of Educational Psychology, 78(2), 313-329.

Kline, R. B. (2005). Principles and practice of structural equation modeling. (2 ed.). New York: The Guilford Press.

Kuo, M. J. (2007) How does an online game based learning environment promote students' intrinsic motivation for learning natural science and how does it affect their. Paper presented at The First IEEE International Workshop on Digital Game and Intelligent Toy Enhanced 
Learning. Jhongli, Taiwan, (March, 2007).

Lavooy, M., \& Newlin, M. (2003). Computer mediated communication: Online Instruction and Interactivity. Journal of Interactive Learning Research, 14(2), 157-165.

Liawm, S. (2008). Investigating students' perceived satisfaction, behavioral intention, and effectiveness of e-learning: A case study of the Blackboard system. Computers \& Education, 51(2), 864-873. http://dx.doi.org/10.1016/j.compedu.2007.09.005.

Lublin, J. (2003). Deep, surface and strategic approaches to learning. Centre for teaching and learning: Good practice in teaching and learning. Retrieved 5 July 2012, from http://www2. warwick.ac.uk/services/ldc/development/pga/introtandl/resources/2a_deep_surfacestrategic_ap proaches_to_learning.pdf

Marton, F., \& Säljö, R. (1976). On qualitative differences in learning I - Outcome and process. The British Journal of Educational Psychology, 46(1), 4-11. http://dx.doi.org/10. 1111/j.2044-8279.1976.tb02980.x.

Matsunga, M. (2010). How to factor-analyse your data right: Do's, don'ts and how-to's. International Journal of Psychological Research, 3(1), 97-110.

Mayer, R. E. (2009). Multimedia learning. (Second ed.). Santa Barbara: Cambridge University press.

Mazur, E. (1997). Peer Instruction: a user's manual. Englewood Cliffs: NJ, Prentice Hall.

Mazur, E. (2009). Farewell, Lecture? Science, 323(50), 51-52. http://dx.doi.org/10.1126/ science. 1168927.

McKeachie, W. (2002). McKeachie's teaching tips: Strategies, research, and theory for college and university teachers (Vol. 11th). Boston: Houghton-Mifflin.

Michael, J. (2006). Where's the evidence that active learning works? Advances in Physiology Education, 30(4), 159-167. http://dx.doi.org/10.1152/advan.00053.2006.

Ministry of Education. (2001). National Plan for Higher Education in South Africa. Pretoria, South Africa.

Mishra, P., \& Koehler, M. J. (2006). Technological pedagogical content knowledge: A framework for integrating technology in teacher knowledge. Teachers College Record, 108(6), 1017-1054. http://dx.doi.org/10.1.1.91.7990.

Mohr, A. T., Holtbrügge, D., \& Berg, N. (2012). Learning style preferences and the perceived usefulness of e-learning. Teaching in Higher Education, 17(3), 309-322. http://dx.doi.org/10.1080/13562517.2011.640999.

Moore, M. G. (1989). Editorial: Three types of interaction. American Journal of Distance Education, 3(2), 1-7. http://dx.doi.org/10.1080/08923648909526659.

Neo, M. (2005). Engaging students in group-based co-operative learning- A Malaysian perspective. Educational Technology \& Society, 8(4), 220-232. 
Offir, B., Lev, Y., \& Bezalel, R. (2008). Surface and deep learning processes in distance education: Synchronous versus asynchronous systems. Computers and Education, 51(3) 1172-1183. http://dx.doi.org/10.1016/j.compedu.2007.10.009.

Patterson, B., Kilpatrick, J., \& Woebkenberg, E. (2010). Evidence for teaching practice: The impact of clickers in a large classroom environment. Nurse Education Today, 30(7), 603-607. http://dx.doi.org/10.1016/j.nedt.2009.12.008.

Phan, H. P. (2009). Relations between goals, self-efficacy, critical thinking and deep processing strategies: a path analysis. Educational Psychology, 29(7), 777-799. http://dx.doi.org/10.1080/01443410903289423.

Perkins, D. V., \& Saris, R. N. (2001). A "Jigsaw Classroom" technique for undergraduate statistics courses. Teaching of Psychology, 28(2), 111-113. http://dx.doi.org/10.1207/ S15328023TOP2802_09.

Perkins, K., \& Turpen, C. (2009). Student perspectives on using clickers in upper-division physics courses, Paper presented at the Physical education research conference, Ann Arbor.

Peters, D., Jones, G., \& Peters, J. (2007). Approaches to studying, academic achievement and autonomy, in higher education sports students. Journal of Hospitality, Leisure, Sport and Tourism Education, 6(2), 16 - 28. http://dx.doi.org/10.3794/johlste.62.132

Pintrich, P. R., \& Schunk, D. H. (1996). Motivation in education: Theory, research, and applications. Columbus: Merrill.

Pintrich, P. R., Smith, D. A. F., Garcia, T. G., \& McKeachie, W. J. (1991). A manual for the use of the Motivated Strategy for Learning Questionnaire (MSLQ). Ann Arbor: National Centre for Research to Improve Post-Secondary Teaching and Learning: University of Michigan.

Richardson, J. T. (2005). Students' approaches to learning and teachers' approaches to teaching in higher education. Educational Psychology, 25(6), 673-680. http://dx.doi.org/10. 1080/01443410500344720.

Ryan, R. M., \& Deci, E. (2000). Intrinsic and extrinsic motivations: Classic definition and new directions. Contemporary educational Psychology, 25(1), 54-67. http://dx.doi.org/ 10.1006/ceps.1999.1020.

Sansone, C., \& Harackiewicz, J. M. (2000). Intrinsic and extrinsic motivation: The search for optimal motivation and performance. San Diego: Academic Press.

Schuck, S., \& Kearney, M. (2008). Classroom-Based Use of Two Educational Technologies: A Sociocultural Perspective. Contemporary Issues in Technology and Teacher Education, $8(4), 394-406$.

Slof, B., Erkens, G., Kirschner, P. A., Jaspers, J. G. M., \& Janssen, J. (2010). Guiding students' online complex learning-task behavior through representational scripting. Computers in Human Behavior, 26(5), 927-939. http://dx.doi.org/10.1016/j.chb.2010.02.007. 
Schmid, R. F., Bernard, R. M., Borokhovski, E., Tamim, R., Abrami, P.C., Wade, C. A., Michael A. Surkes, M. A. \& G. Lowerison (2009). Technology's effect on achievement in higher education: a Stage I meta-analysis of classroom applications. Journal of Computing in High Education, 21:95-109. http://dx.doi.org/10.1007/s12528-009-9021-8.

Solvie, P., \& Kloek, M. (2007). Using technology tools to engage students with multiple learning styles in a constructivist learning environment. Contemporary Issues in Technology and Teacher Education, 7(2), 7-27.

Tarabashkina, L. (2011). The impact of values and learning approaches on student achievement: Gender and academic discipline influences. Issues In Educational Research, 21(2), 210-231.

Ullah, H., \& Wilson, M. A. (2007). Students' academic success and its association to student involvement with learning and relationships with faculty and peers. College Student Journal, 41(4), 1192-1202.

Vrasidas, C., \& McIsaac, M. S. (2001). Integrating technology in teaching and teacher education: Implications for policy and curriculum reform. Educational Media International, $38(2-3), 127-132$.

Warburton, K. (2003). Deep learning and education for sustainability. International Journal of Sustainability in Higher Education, 4 Iss(1), 44 - 56. http://dx.doi.org/10.1108/ 14676370310455332.

Winn, W. (2002). Current trends in educational technology research: the study of learning environments. Educational Psychology Review, 14(3), 331-351. http://dx.doi.org/10.1023/A: 1016068530070 .

Wishart, J., \& Blease, D. (1999). Theories underlying perceived changes in teaching and learning after installing a computer network in a secondary school. British Journal of Educational Technology, 30(1), 25-42. http://dx.doi.org/10.1111/1467-8535.00088.

Yoder, J., \& Hochevar, C. (2005). Encouraging active learning can improve students' performance on examinations. Teaching of Psychology, 32(2), 91-95.

Zandvleit, D. B., \& Fraser, B. J. (2004). Learning environments in information and communications technology classroom. Technology Pedagogy and Education, 13(1), 97-124. http://dx.doi.org/10.1080/14759390400200175.

\section{Copyright Disclaimer}

Copyright reserved by the author(s).

This article is an open-access article distributed under the terms and conditions of the Creative Commons Attribution license (http://creativecommons.org/licenses/by/3.0/). 